\title{
Determining Optimal Portfolio in a Three-Asset Portfolio Mix in Nigeria
}

\author{
Amenawo I. Offiong1, Hodo B. Riman ${ }^{1 *}$, Eyoanwan E. Eyo ${ }^{2}$ \\ ${ }^{1}$ Department of Banking and Finance, University of Calabar, Calabar, Nigeria \\ ${ }^{2}$ Department of Mathematics and Statistics, University of Calabar, Calabar, Nigeria \\ Email: ameofiong@yahoo.com, ‘horim105@yahoo.com,diamondeyo@gmail.com
}

How to cite this paper: Offiong, A.I., Riman, H.B. and Eyo, E.E. (2016) Determining Optimal Portfolio in a Three-Asset Portfolio Mix in Nigeria. Journal of Mathematical Finance, 6, 524-540. http://dx.doi.org/10.4236/jmf.2016.64041

Received: July 16, 2016

Accepted: October 8, 2016

Published: October 11, 2016

Copyright (c) 2016 by authors and Scientific Research Publishing Inc. This work is licensed under the Creative Commons Attribution International License (CC BY 4.0).

http://creativecommons.org/licenses/by/4.0/ (c) (i) Open Access

\begin{abstract}
This study is aimed at determining the optimal portfolio in a three-asset portfolio mix in Nigeria. The research employed majorly two empirical methodologies which were Matrix algebra and Lagrangian method of optimization. Matrix algebra was used to compute the various portfolio weights. Lagrangian method of optimization was useful in obtaining the global minimum variance and the efficient frontier of the portfolio. In order to arrive at the best asset in the portfolio that is expected to yield maximum expected return, the study employed the utility function test. The data used for the study were daily stock prices for First Bank Nigeria Plc, Guinness Nigeria Plc and Cadbury Nigeria Plc obtained from the Nigerian Stock Exchange for the period of January 2010 to December 2013 The result obtained from the analysis indicated that among the three assets chosen in the study, Guinness has the highest utility value of 0.031 with lowest risk of 4.268 and the investment opportunity point $(\mu, \sigma)$ which is $(0.169,2.065)$ lies on the Capital Market Line. The assets of Guinness and First Bank are located above the Global Minimum at point $(\mu, \sigma)$ which is $(0.10,1.84)$ and are said to be efficient assets with high expected returns and low risk. The study therefore concluded that First Bank and Guinness were the only efficient optimal assets in the three asset-portfolio mix and therefore, the preferred choice for every investor since they yielded a high return with minimum variance.
\end{abstract}

\section{Keywords}

Covariance, Optimal Portfolio, Efficient Frontier, Portfolio Mix, Asset Diversification, Correlation Matrix, Global Minimum Variance

\section{Introduction}

The world of investment is strikingly full of uncertainty as investors face the possibility 
of either making gain or losing a fraction or even sometimes their entire investment funds. Every investor is faced with the decision of either holding back his investible funds (particularly, if the magnitude of returns on his proposed investment in not known) or invest all the same assuming he is a risk taker. Most investors hold their baskets of investment in more than just one or two portfolio for the obvious reason of diversification which is intended to minimize risk on the investment. Accordingly, [1] was quick to posit that, the main goal of such investors constructing such portfolio was to basically in an attempt to "strike a balance" between mainly two conflicting objectives, namely, making a maximum return/profit at the most minimum risk possible given that a wise choice of constituent assets was made and the proper fraction of investment funds was allocated correspondingly.

Harry Markowitz's mean-variance portfolio model, which is the foundation of modern portfolio theory, assumes that all available information and expectations on future prices are contained in the current prices of assets, and thus treat future payoffs and returns as random variable. In simple terms, it can be assumed that the returns of an asset (say asset $i$ ), follow a Gaussian distribution in which the expected mean value of the returns, $\hat{r}$ and their variance $\delta^{2}$ capture all the information concerning the expected outcome, likelihoods and range of deviations from it [1]. However, the common feature of most investment is that the actual returns on investment sometimes vary significantly from their expected returns. The magnitude of such variances is often predicated on the level of information asymmetry that exists in the market. This is the risk that is mostly inherent in all financial assets and thus, necessitates a careful selection of investment portfolio by investors.

In choosing or combining assets in a portfolio, it is important for investors to know the degree of covariance that exists between the assets. Covariance reflects the degree to which the returns of two securities vary or change together. For instance, assets that have a positive upward co-movement will tend to reduced returns, while assets that have a downward and negative co-movement tend to yield increase returns. Thus, upward and downward deviations from the expected return will and can be reduced through diversification since diversification has the ability to reduce the variance of expected even when both have the same magnitude of expected return. As the number of securities included in a portfolio increases, the importance of the risk of each individual security decreases whereas the significance of the covariance relationship increases [2]

Arguably, only very few investors have recognized the role of diversification in portfolio risk reduction, while others are ignorant about it. The idea of identifying the appropriate asset mix is the main role in determining the portfolio risk and return. For every portfolio investment strategy, overcoming the problems of selection and allocation of investment funds to the constituent assets are of major concern to many investors [3] [4]. A potential portfolio investor should plan his investment objectives which should be stated in terms of return and risk tolerance. While stating his objectives, the investor should consider the constraints arising out of some factors like liquidity, which is the speed with which an asset can be sold. 
Allocation of investment capital in a three-asset portfolio mix constitutes a problem to potential investors, institutions and corporate organizations. Several investors in Nigeria often face the difficulty of how to allocate their capital to companies quoted in the stock market in order to maximize returns while minimizing risk as ultimate goal. Apart from investors facing the challenge of selecting the type of asset to invest in, they also lack technical knowledge on how to allocate their funds to the selected portfolio. Most available literatures have enunciated portfolio selection given two assets while ignoring the case of multi-assets mix in a portfolio. This study intends to show how to determine the optimal portfolio in a three-asset portfolio mix through understanding 1) how to determine the fraction capital that should be allocated to the various assets 2) how to obtain a maximum expected return at the most minimum risk 3) how to determine the optimal portfolio among all possible efficient portfolios and 4) how to determine the best asset in a three-asset portfolio mix. The research utilizes daily stock prices for the period 2010 to 2013 from the Nigerian Stock Exchange for three institutional investors, viz, First Bank Nigeria Plc, Guinness Nigeria Plc and Cadbury Nigeria Plc.

\section{Review of Related Literature}

Several studies have been conducted on Portfolio theory due to its vital importance in finance literature though pioneered by [5] and popularized by [6]-[11]

Introducing the model for Portfolio selection and stating the two stages of Portfolio selection, [5] stated that the first stage starts from examination and ended the principle with the opinion about the potential performance of available securities. The second stage of this principle begins from the relevant views on the potential performance of securities and ended with the selection of Portfolio. Focus of Markowitz study was the second stage of Portfolio selection. The model developed by Markowitz works on the mechanism of expected rate of return and expected risk of Portfolio.

Estimating utility by a function of mean and variance of return of 149 mutual funds, [12] found that ordering portfolios by mean-variance rule was almost identical to the order obtained by using expected utility. The mean-variance formulation provides a very good local approximation to expected utility functions using both monthly and semi-annual return data [13]. According to the study, investors can confidently rely on mean-variance optimization, with attitude towards local changes in portfolio value reflected by the local relative risk-aversion.

Investigating the optimal holding period (investment horizon) for the classical meanvariance portfolio model, [14] used the historical transaction record of Istanbul Stock Exchange ISE-100 index stocks data for empirical analysis. The results of the study showed that portfolio returns with varying holding period has a convex structure with an optimal holding period.

While investigating optimal portfolio allocation in a world without treasury securities, Bomfim [15] examined the extent to which investors' portfolio allocation decisions are likely to be affected by the retirement of all federal government debt. He noted that, if current projections of future budget surpluses materialize, investing in Treasury se- 
curities-an asset class with which investors have long been familiar-could eventually become a thing of the past. Thus, under such circumstances, highly conservative investors-whose portfolios have risk-return characteristics akin to money market instruments-and very aggressive investors-that hold mostly equities-stand to be the least affected by the removal of Treasuries from the pool of investable assets.

[16] sought to determine the relationship between portfolio risk and portfolio size, the optimal portfolio size in the Nairobi Securities Exchange and the extent of risk reduction achieved by diversification. The results of the study indicate that diversification results in risk reduction benefits. Portfolio risk decreased as the number of securities in the portfolio increased. Their result further observed that Risk reduction is initially rapid with risk reduction of $40 \%$ is achieved with a portfolio size of 8 securities. Adding 8 more securities achieves a further $5 \%$ reduction in portfolio risk while the next 14 additional securities achieves only a further $2 \%$ risk reduction.

[17] used linear programing model to determine optimal portfolio mix for Multigrow Insurance Company in Ghana who had obtained GHC 200,000 cash facility but were experiencing difficulties in determining how much to invest in each of five investment areas in order to maximize return. Based on the methodology used optimal portfolio mix was obtained for the Insurance Company.

[18] explored which asset classes add value to a traditional portfolio of stocks, bonds and cash by using ten different investment categories simultaneously in a mean-variance analysis as well as a market portfolio approach. The study further sought to determine the optimal weights of all asset classes in the optimal portfolio. The mean-variance analysis suggested that real estate, commodities and high yield add most value to the traditional asset mix of stocks, bonds and cash. The authors further opined that adding these three asset classes comes close to an all asset portfolio. The portfolio with all assets showed a diversification benefit along the efficient frontier that varies between $0.40 \%$ and $0.93 \%$ in the volatility range of $7 \%$ to $20 \%$. Based on their analysis the authors concluded that the proportion of non-traditional asset classes appearing in the market portfolio is relatively small, and thus, investors must determine their own individual constraints, while the market portfolio and the portfolio optimized by mean-variance are considered as the boundaries for the asset classes.

[19] examined and developed a sensitivity analysis for differential risk premiums in REIT stocks and the effect in determining an optimal port-folio mix by applying mean variance analysis in the US financial markets. Furthermore, the study used the meanvariance approach to illustrate ways to maximize the utility of the optimal portfolio with varying degrees of risk aversion. Two different risk premiums between stocks and bonds, such as $0.006 \%$ and $0.012 \%$ were applied to examine the portfolio choices. Their result showed that when the risk premium of REITs and stocks was $1.5 \%$, investors with risk aversion equal to 1 to 6 were better off investing almost all capital in REITs. The study suggested that this group of investors can short sell their bonds and put a very small weight in stocks. Furthermore, investors can also derive the same benefit even when the risk premium of REITs and stock is $2.0 \%$ with a risk aversion of 1 to 9 . 
However, when the risk premium of REITs and stock is $2.5 \%$, the investor's risk aversion factor does not matter, and it suggests that investors can short sell bonds and invest in REITs having a larger weight in the optimal portfolio.

\subsection{Determination of Optimal Portfolio}

Following [20], the rule for selecting the best asset is known as utility function test of the portfolio. Utility refers to the expected return of the portfolio minus risk penalty. The risk penalty is given by:

$$
\text { Risk penalty }=\frac{\text { Risk squared }}{\text { Risk tolerance }}
$$

Risk squared is the variance of the portfolio and risk tolerance is a number from 0 through 100. It is difficult to define the concept of risk tolerance precisely because the level is set by financial situation or financial disposition and preference of an investor. The concept of risk tolerance depends on the behavioral pattern of investors. For instance, if an investor experiences an increase in wealth, he/she will choose to increase (or keep unchanged, or decrease) the fraction of the portfolio held in the risky asset if relative risk aversion is decreasing (constant, or increasing). Thus, the capacity to bear the risk of losses without being upset depends on financial ability and personal temperament. Thus, the best asset for investment would be the one from the efficient frontier that maximizes the utility.

\subsection{Mathematical Modeling of Two Risky Assets}

Consider a portfolio containing two financial assets, the investor's decision may be based on the expected returns and variances which are the two sufficient parameters in which normal distribution may be defined [21]. Therefore, the expected value or return represents the weighted average rates of return while the variance represents the level of risk.

Assume that there is a utility function of the type

$$
\text { Utility }=f(\text { return; risk })
$$

Any rational investors would seek to maximize or minimize the utility. That is, maximum expected return at a given level of risk or minimum risk at a given level of return. If we assume that there are only two risky assets, A and B, available for consideration in an investment portfolio. Since the portfolio contains two assets of different proportions, $x$ and $(1-x)$, the functional relationship between risk and return can be easily determined [22].

In this case, we have

$$
R_{p}=x_{A} R_{A}+x_{B} R_{B}
$$

where $R_{P}$ is the portfolio return, $x_{A}$ and $x_{B}$ are the portfolio weights.

The portfolio weights sum to one 


$$
x_{A}+x_{B}=1
$$

by taking expectation of equation (6)

$$
E\left(R_{p}\right)=x_{A} E\left(R_{A}\right)+x_{B} E\left(R_{B}\right)
$$

the mean portfolio return is found to be

$$
\mu_{p}=x_{A} \mu_{A}+x_{B} \mu_{B}
$$

Consequently the portfolio variance is

$$
\sigma_{p}^{2}=x_{A}^{2} \sigma_{A}^{2}+x_{B}^{2} \sigma_{B}^{2}+2 x_{A} x_{B} \rho_{A B} \sigma_{A} \sigma_{B}
$$

and the portfolio standard deviation is

$$
\sigma_{\rho}=\sqrt{x_{A}^{2} \sigma_{A}^{2}+\left(1-x_{A}\right)^{2} \sigma_{B}^{2}+2 x_{A}\left(1-x_{A}\right) \rho_{A B} \sigma_{A} \sigma_{B}}
$$

\subsection{Mathematical Formulation of Minimum Risk Two-Asset Portfolio Mix}

Let $u=x_{A}^{2} \sigma_{A}^{2}+\left(1-x_{A}\right)^{2} \sigma_{B}^{2}+2 x_{A}\left(1-x_{A}\right) \rho_{A B} \sigma_{A} \sigma_{B}$

$$
\begin{gathered}
\sigma_{p}=\sqrt{u} \text { and } \frac{\mathrm{d} \sigma_{p}}{\mathrm{~d} u}=\frac{1}{2 \sqrt{u}} \\
\frac{\mathrm{d} u}{\mathrm{~d} x_{A}}=2 x_{A} \sigma_{A}^{2}-2\left(1-x_{A}\right) \sigma_{B}^{2}+2 \rho_{A B} \sigma_{A} \sigma_{B}-4 x_{A} \rho_{A B} \sigma_{A} \sigma_{B} \\
=2 x_{A} \sigma_{A}^{2}-2\left(1-x_{A}\right) \sigma_{B}^{2}+2 \rho_{A B} \sigma_{A} \sigma_{B}-2 x_{A} \rho_{A B} \sigma_{A} \sigma_{B}-2 x_{A} \rho_{A B} \sigma_{A} \sigma_{B} \\
=2 x_{A} \sigma_{A}^{2}-2\left(1-x_{A}\right) \sigma_{B}^{2}+2\left(1-x_{A}\right) \rho_{A B} \sigma_{A} \sigma_{B}-2 x_{A} \rho_{A B} \sigma_{A} \sigma_{B}
\end{gathered}
$$

The minimum Risk Portfolio is obtained by minimizing the portfolio standard deviation. Taking the first derivative of Equation (11) with respect to $x_{A}$, we obtain

$$
\begin{gathered}
\frac{\mathrm{d} \sigma_{p}}{\mathrm{~d} x_{A}}=\frac{\mathrm{d} \sigma_{p}}{\mathrm{~d} u} \cdot \frac{\mathrm{d} u}{\mathrm{~d} x_{A}} \\
\frac{\mathrm{d} \sigma_{\rho}}{\mathrm{d} x_{A}}=\frac{2 x_{A} \sigma_{A}^{2}-2\left(1-x_{A}\right) \sigma_{B}^{2}+2\left(1-x_{A}\right) \rho_{A B} \sigma_{A} \sigma_{B}-2 x_{A} \rho_{A B} \sigma_{A} \sigma_{B}}{2 \sqrt{x_{A}^{2} \sigma_{A}^{2}+\left(1-x_{A}\right)^{2} \sigma_{B}^{2}+2 x_{A}\left(1-x_{A}\right) \rho_{A B} \sigma_{A} \sigma_{B}}}
\end{gathered}
$$

To minimize $\sigma_{P}$, set the first order derivative to zero;

$$
\begin{gathered}
\frac{\mathrm{d} \sigma_{p}}{\mathrm{~d} x_{A}}=0 \\
\frac{2 x_{A} \sigma_{A}^{2}-2\left(1-x_{A}\right) \sigma_{B}^{2}+2\left(1-x_{A}\right) \rho_{A B} \sigma_{A} \sigma_{B}-2 x_{A} \rho_{A B} \sigma_{A} \sigma_{B}}{2 \sqrt{x_{A}^{2} \sigma_{A}^{2}+\left(1-x_{A}\right)^{2} \sigma_{B}^{2}+2 x_{A}\left(1-x_{A}\right) \rho_{A B} \sigma_{A} \sigma_{B}}}=0 \\
2 x_{A} \sigma_{A}^{2}-2\left(1-x_{A}\right) \sigma_{B}^{2}+2\left(1-x_{A}\right) \rho_{A B} \sigma_{A} \sigma_{B}-2 x_{A} \rho_{A B} \sigma_{A} \sigma_{B}=0
\end{gathered}
$$

We make $x_{A}$ the subject

$$
\begin{gathered}
2 x_{A} \sigma_{A}^{2}-2 \sigma_{B}^{2}+2 x_{A} \sigma_{B}^{2}+2 \rho_{A B} \sigma_{A} \sigma_{B}-2 x_{A} \rho_{A B} \sigma_{A} \sigma_{B}-2 x_{A} \rho_{A B} \sigma_{A} \sigma_{B}=0 \\
2 x_{A} \sigma_{A}^{2}+2 x_{B} \sigma_{B}^{2}-2 x_{A} \rho_{A B} \sigma_{A} \sigma_{B}-2 x_{A} \rho_{A B} \sigma_{A} \sigma_{B}=2 \sigma_{B}^{2}-2 \rho_{A B} \sigma_{A} \sigma_{B}
\end{gathered}
$$




$$
x_{A}\left(2 \sigma_{A}^{2}+2 \sigma_{B}^{2}-2 \rho_{A B} \sigma_{A} \sigma_{B}-2 \rho_{A B} \sigma_{A} \sigma_{B}\right)=2 \sigma_{B}^{2}-2 \rho_{A B} \sigma_{A} \sigma_{B}
$$

Solving (11) for $x_{A}$ leads to

$$
\begin{gathered}
x_{A}=\frac{2 \sigma_{B}^{2}-2 \rho_{A B} \sigma_{A} \sigma_{B}}{2 \sigma_{A}^{2}+2 \sigma_{B}^{2}-2 \rho_{A B} \sigma_{A} \sigma_{B}-2 \rho_{A B} \sigma_{A} \sigma_{B}} \\
x_{A}=\frac{\sigma_{B}^{2}-\rho_{A B} \sigma_{A} \sigma_{B}}{\sigma_{A}^{2}+\sigma_{B}^{2}-2 \rho_{A B} \sigma_{A} \sigma_{B}}
\end{gathered}
$$

The sufficient condition for $\sigma_{p}$ to have a global minimum value at $x_{A}$ is that $\left.\frac{\mathrm{d}^{2} \sigma_{p}}{\mathrm{~d} x_{A}^{2}}\right|_{\chi_{A}}=\frac{\sigma_{B}^{2}-\rho_{A B} \sigma_{A} \sigma_{B}}{\sigma_{A}^{2}+\sigma_{B}^{2}-2 \rho_{A B} \sigma_{A} \sigma_{B}} \succ 0$

The degree of correlation between two assets $A$ and $B$ is used to determine the shape of the frontier within the portfolio. There are three assumptions about the correlation between two assets $\mathrm{A}$ and $\mathrm{B}$.

1) Perfect positive correlation, $\rho=1$

We simplify Equation (7) as:

$$
\sigma_{\rho}^{2}=x_{A}^{2} \sigma_{A}^{2}+x_{B}^{2} \sigma_{B}^{2}+2 x_{A} x_{B} \sigma_{A} \sigma_{B}
$$

When the correlation coefficient assumes the value +1 it means that all the points in the scattered diagram lie on the same straight line. Thus, the slope is positive which means that while the value of asset $A$ is increasing, the value of $B$ is also increasing or the value of $A$ decreases as $B$ decreases [23].

2) Perfect negative correlation, $\rho=-1$

We simplify Equation (10) as:

$$
\sigma_{\rho}^{2}=x_{A}^{2} \sigma_{A}^{2}+x_{B}^{2} \sigma_{B}^{2}-2 x_{A} x_{B} \sigma_{A} \sigma_{B}
$$

When the correlation coefficient assumes the value -1 it means that the slope is negative that is while one of the assets is increasing the other is decreasing [23].

3) Non-perfect correlation, $\rho=0$

When the correlation coefficient takes the value zero, it means that there is no linear relationship between the assets $\mathrm{A}$ and $\mathrm{B}$ or that assets $\mathrm{A}$ and $\mathrm{B}$ are linearly uncorrelated [23]. Therefore, we simplify Equation (10) as:

$$
\begin{gathered}
\sigma_{p}^{2}=x_{A}^{2} \sigma_{A}^{2}+x_{B}^{2} \sigma_{B}^{2} \\
\sigma_{p}=\sqrt{\left(x_{A}^{2} \sigma_{A}^{2}+x_{B}^{2} \sigma_{B}^{2}\right)}
\end{gathered}
$$

Consider the mean and standard deviation in the relationship derived from the equations (9) and (16) respectively. We can write the slope of the frontier as:

$$
\frac{\mathrm{d} \mu_{p}}{\mathrm{~d} \sigma_{\rho}}=\frac{\mathrm{d} \mu / \mathrm{d} x_{A}}{\mathrm{~d} \sigma_{P} / \mathrm{d} x_{A}}=\frac{\mu_{A}-\mu_{B}}{\left(x_{A} \sigma_{A}^{2}-x_{B} \sigma_{B}^{2}\right) / \sigma_{\rho}}
$$

If we assume that $\mu_{A}>\mu_{B}$ and $\sigma_{A}>\sigma_{B}$, the sign of the slope in Equation (17) depends on the denominator. Notice that the slope is vertical at some point and portfolio which produce this point is known as minimum variance portfolio [18]. 


\section{Research Methodology}

The study utilized daily stock prices for First Bank Nigeria Plc, Guinness Nigeria Plc and Cadbury Nigeria Plc from January 2010-December 2013. The choice of assets was determined by their high level of stock returns among other stocks in their sub-sectors. Stock returns was calculated as thus,

Average rate of return $\bar{R}$ expressed as:

$$
\begin{gathered}
\bar{R}=\frac{1}{n}\left[R_{1}+R_{2}+\cdots+R_{n}\right] \\
\bar{R}=\frac{1}{n} \sum_{i=1}^{n} R_{i}
\end{gathered}
$$

where:

$R=$ rate of return.

$n=$ number of returns.

The stock return in any time period is given as

$$
R E T=\ln \left(P_{t} / P_{t-1}\right) \times 100
$$

where:

$P_{t}$ is the price at current time.

$P_{t-1}$ is the price at previous time.

\subsection{Modeling a Three-Asset Portfolio Mix}

Previously, we had model a two-asset mix, this model is common in most literatures and books. However, it is not common to find a model for a three-asset mix portfolio. If we consider a portfolio containing three financial assets (A, B and $\mathrm{C}$ ), recourse is taken to matrix algebra which can represent a lot of data by putting them into groups which are called rectangular arrays. It is assumed that investors may invest in a total of three risky assets.

Suppose $R_{i} \quad(i=A, B, C)$ indicate the return on asset $i$ with an assumption that the constant expected return (CER) model holds:

$$
\begin{gathered}
R_{i} \sim \text { iid } N\left(\mu_{i}, \sigma_{i}^{2}\right) \\
\operatorname{cov}\left(R_{i}, R_{j}\right)=\sigma_{i j} .
\end{gathered}
$$

Suppose $x$ represents the fraction of capital in asset $i(i=A, B, C)$ and assume that all capital is invested in the three assets so that $x_{A}+x_{B}+x_{C}=1$.

The return for the portfolio $R_{p, x}$ is

$$
R_{p, x}=x_{A} R_{A}+x_{B} R_{B}+x_{C} R_{C}
$$

Taking expectations of both sides of the above equation we obtain

$$
E\left[R_{p, x}\right]=x_{A} E\left[R_{A}\right]+x_{B} E\left[R_{B}\right]+x_{C} E\left[R_{C}\right]
$$

This may be re-written as

$$
\mu_{p, x}=x_{A} \mu_{A}+x_{B} \mu_{B}+x_{C} \mu_{C}
$$


where

$$
\mu_{p, x}=E\left[R_{p, x}\right], \mu_{A}=E\left[R_{A}\right], \mu_{B}=\left[R_{B}\right] \text { and } \mu_{C}=E\left[R_{C}\right]
$$

Variance of the portfolio is written as

$$
\begin{aligned}
\sigma_{p, x}^{2}=\operatorname{var}\left(R_{p, x}\right)= & x_{A}^{2} \sigma_{A}^{2}+x_{B}^{2} \sigma_{B}^{2}+x_{C}^{2} \sigma_{C}^{2}+2 x_{A} x_{B} \sigma_{A B} \\
& +2 x_{A} x_{C} \sigma_{A C}+2 x_{B} x_{C} \sigma_{B C}
\end{aligned}
$$

It is observed that the variance of the portfolio return is dependent on three variance terms and six covariance terms. Therefore, the covariance terms are twice of the variance terms which contribute to the variance of the portfolio. Matrix notation can be used to simplify the portfolio algebra for easy calculation [22].

\subsection{Finding the Global Minimum Variance Portfolio}

Let $m=\left(m_{A}, m_{B}, m_{C}\right)^{\prime}$ be global minimum variance portfolio for three assets which is obtained by solving the constrained minimization problem. Following [4], the constrained minimization problem is given by:

$$
\begin{aligned}
& \min _{m_{A}, m_{B}, m_{C}} \sigma_{p, m}^{2}= m_{A}^{2} \sigma_{A}^{2}+m_{B}^{2} \sigma_{B}^{2}+m_{C}^{2} \sigma_{C}^{2}+2 m_{A} m_{B} \sigma_{A B} \\
&+2 m_{A} m_{C} \sigma_{A C}+2 m_{B} m_{C} \sigma_{B C} \\
& \text { s.t } m_{A}+m_{B}+m_{C}=1
\end{aligned}
$$

The lagrangian for this problem is

$$
\begin{aligned}
L\left(m_{A}, m_{B}, m_{C}, \lambda\right)= & m_{A}^{2} \sigma_{A}^{2}+m_{B}^{2} \sigma_{B}^{2}+m_{C}^{2} \sigma_{C}^{2}+2 m_{A} m_{B} \sigma_{A B}+2 m_{A} m_{C} \sigma_{A C} \\
& +2 m_{B} m_{C} \sigma_{B C}+\lambda\left(m_{A}+m_{B}+m_{C}-1\right)
\end{aligned}
$$

and the first order conditions (FOCs) for a minimum are

$$
\begin{aligned}
& 0=\frac{\partial L}{\partial m_{A}}=2 m_{A} \sigma_{A}^{2}+2 m_{B} \sigma_{A B}+2 m_{C} \sigma_{A C}+\lambda, \\
& 0=\frac{\partial L}{\partial m_{B}}=2 m_{B} \sigma_{B}^{2}+2 m_{A} \sigma_{A B}+2 m_{C} \sigma_{B C}+\lambda, \\
& 0=\frac{\partial L}{\partial m_{C}}=2 m_{C} \sigma_{C}^{2}+2 m_{A} \sigma_{A C}+2 m_{B} \sigma_{B C}+\lambda, \\
& 0=\frac{\partial L}{\partial \lambda}=m_{A}+m_{B}+m_{C}-1 .
\end{aligned}
$$

The above conditions are made up of four linear equations in four unknowns. It can be solved to obtain the weights of global minimum. The four linear equations describing the first order conditions have the matrix representation.

$$
\left(\begin{array}{cccc}
2 \sigma_{A}^{2} & 2 \sigma_{A B} & 2 \sigma_{A C} & 1 \\
2 \sigma_{A B} & 2 \sigma_{B}^{2} & 2 \sigma_{B C} & 1 \\
2 \sigma_{A C} & 2 \sigma_{B C} & 2 \sigma_{C}^{2} & 1 \\
1 & 1 & 1 & 0
\end{array}\right)\left(\begin{array}{c}
m_{A} \\
m_{B} \\
m_{C} \\
\lambda
\end{array}\right)=\left(\begin{array}{l}
0 \\
0 \\
0 \\
1
\end{array}\right)
$$

or, more concisely,

$$
\left(\begin{array}{cc}
2 \Sigma & I \\
I^{\prime} & 0
\end{array}\right)\left(\begin{array}{l}
m \\
\lambda
\end{array}\right)=\left(\begin{array}{l}
0 \\
1
\end{array}\right)
$$


where

$\sum$ is the covariance matrix.

$I$ is the identity matrix.

$I^{\prime}$ is the transpose of $I$.

$m$ is the global minimum variance portfolio weights.

$\lambda$ is the Lagrange multiplier.

The system (25) is of the form

$$
A_{m} Z_{m}=b
$$

where

$$
A_{m}=\left(\begin{array}{cc}
2 \Sigma & I \\
I^{\prime} & 0
\end{array}\right), z_{m}=\left(\begin{array}{l}
m \\
\lambda
\end{array}\right) \text { and } b=\left(\begin{array}{l}
0 \\
1
\end{array}\right)
$$

Then the solution for $z_{m}$ is

$$
Z_{m}=A_{m}^{-1} b
$$

Portfolio weights $m=\left(m_{A}, m_{B}, m_{C}\right)^{\prime}$ consist of the first three elements of $z_{m}$ for the global minimum variance portfolio with expected return $\mu_{p, m}=m^{\prime} \mu$ and variance $\sigma_{p, m}^{2}=m^{\prime} \Sigma m$ [4].

\subsection{Finding Efficient Portfolios}

There are two methods of finding efficient portfolios [4]. First, investors seek to maximize the portfolio expected return for a given level of risk. Let $\sigma_{p, 0}^{2}$ denote a target level of risk. The constrained maximization problem is defined as:

$$
\begin{aligned}
& \max _{x} \mu_{p}=x^{\prime} \mu \\
& \text { s.t } x^{\prime} \sum x=\sigma_{p, 0}^{2} \text { and } x^{\prime} 1=1
\end{aligned}
$$

Secondly, minimize the risk of portfolio for a given level of return. Let $\mu_{p, 0}$ denote a target expected return level.

$$
\begin{aligned}
& \min _{x} \sigma_{p, x}^{2}=x^{\prime} \Sigma x \\
& \text { s.t } x^{\prime} \mu=\mu_{p, 0} \text { and } x^{\prime} 1=1,
\end{aligned}
$$

The investor in practice prefers to embrace the target expected returns rather to target risk levels. Thus, the second problem in Equation (28) is most often solved.

To solve the constrained minimization problem (11), first form the Lagrangian function.

$$
\begin{aligned}
& \min _{x_{A}, x_{B} x_{C}} \sigma_{p, x}^{2}=x_{A}^{2} \sigma_{A}^{2}+x_{B}^{2} \sigma_{B}^{2}+x_{C}^{2} \sigma_{C}^{2}+2 x_{A} x_{B} \sigma_{A B}+2 x_{A} x_{C} \sigma_{A C}+2 x_{B} x_{C} \sigma_{B C} \\
& \text { s.t. } x_{A} \mu_{A}+x_{B} \mu_{B}+x_{C} \mu_{C}=\mu_{p, 0} \\
& \quad x_{A}+x_{B}+x_{c}=1
\end{aligned}
$$

The lagrangian for this problem is

$$
\begin{aligned}
L\left(x_{A}, x_{B}, x_{C}, \lambda_{1}, \lambda_{2}\right)= & x_{A}^{2} \sigma_{A}^{2}+x_{B}^{2} \sigma_{B}^{2}+x_{C}^{2} \sigma_{C}^{2}+2 x_{A} x_{B} \sigma_{A B}+2 x_{A} x_{C} \sigma_{A C}+2 x_{B} x_{C} \sigma_{B C} \\
& +\lambda_{1}\left(x_{A} \mu_{A}+x_{B} \mu_{B}+x_{C} \mu_{C}-\mu_{p, 0}\right)+\lambda_{2}\left(x_{A}+x_{B}+x_{C}-1\right)
\end{aligned}
$$


The first order conditions for a minimum are the linear equations.

$$
\begin{aligned}
& 0=\frac{\partial L}{\partial x_{A}}=2 x_{A} \sigma_{A}^{2}+2 x_{B} \sigma_{A B}+2 x_{C} \sigma_{A C}+\lambda_{1} \mu_{A}+\lambda_{2}, \\
& 0=\frac{\partial L}{\partial x_{B}}=2 x_{B} \sigma_{B}^{2}+2 x_{A} \sigma_{A B}+2 x_{C} \sigma_{B C}+\lambda_{1} \mu_{B}+\lambda_{2}, \\
& 0=\frac{\partial L}{\partial x_{C}}=2 x_{C} \sigma_{C}^{2}+2 x_{A} \sigma_{A C}+2 x_{B} \sigma_{B C}+\lambda_{1} \mu_{C}+\lambda_{2}, \\
& 0=\frac{\partial L}{\partial \lambda_{1}}=x_{A} \mu_{A}+x_{B} \mu_{B}+x_{C} \mu_{C}-\mu_{P, 0}, \\
& 0=\frac{\partial L}{\partial \lambda_{2}}=x_{A}+x_{B}+x_{C}-1 .
\end{aligned}
$$

The above conditions are made up of five linear equations in five unknowns, $\left(x_{A}, x_{B}, x_{C}, \lambda_{1}, \lambda_{2}\right)$ In matrix algebra, it is represented as:

$$
\begin{gathered}
{\left[\begin{array}{ccccc}
2 \sigma_{A}^{2} & 2 \sigma_{A B} & 2 \sigma_{A C} & \mu_{A} & 1 \\
2 \sigma_{A B} & 2 \sigma_{B}^{2} & 2 \sigma_{B C} & \mu_{B} & 1 \\
2 \sigma_{A C} & 2 \sigma_{B C} & 2 \sigma_{C}^{2} & \mu_{C} & 1 \\
\mu & \mu & \mu & 0 & 0 \\
1 & 1 & 1 & 0 & 0
\end{array}\right]\left[\begin{array}{c}
x_{A} \\
x_{B} \\
x_{C} \\
\lambda_{1} \\
\lambda_{2}
\end{array}\right]=\left[\begin{array}{c}
0 \\
0 \\
0 \\
\mu_{p, 0} \\
1
\end{array}\right]} \\
{\left[\begin{array}{ccc}
2 \Sigma & \mu & 1 \\
\mu^{\prime} & 0 & 0 \\
1^{\prime} & 0 & 0
\end{array}\right]\left(\begin{array}{c}
x \\
\lambda_{1} \\
\lambda_{2}
\end{array}\right)=\left(\begin{array}{c}
0 \\
\mu_{p, 0} \\
1
\end{array}\right)}
\end{gathered}
$$

The system above is of the form

$$
A z_{x}=b_{0}
$$

where

$$
A=\left(\begin{array}{ccc}
2 \Sigma & \mu & 1 \\
\mu^{\prime} & 0 & 0 \\
1^{\prime} & 0 & 0
\end{array}\right), z_{x}=\left(\begin{array}{c}
\times \\
\lambda_{1} \\
\lambda_{2}
\end{array}\right) \text { and } b_{0}=\left(\begin{array}{c}
0 \\
\mu_{p, 0} \\
1
\end{array}\right)
$$

Then the solution for $Z_{x}$ is

$$
z_{x}=A^{-1} b_{0}
$$

Portfolio weights $x=\left(x_{A}, x_{B}, x_{C}\right)^{\prime}$ consist of the first three elements of $z_{x}$ for minimum variance portfolio with expected return $\mu_{p, x}=\mu_{p, 0}$. If $\mu_{p, 0}$ is greater than or equal to the expected return on the global minimum variance portfolio then $x$ is an efficient portfolio [4].

\subsection{Plotting Efficient Frontier}

Analytical expression for a minimum variance portfolio can be used to show that any minimum variance portfolio can be created as a convex combination of any two minimum variance portfolios with different target expected returns. If the expected return on the resulting portfolio is greater than the expected return on the global minimum 
variance portfolio, then the portfolio is an efficient frontier portfolio. Otherwise, the portfolio is an inefficient frontier portfolio. Thus, to compute the portfolio frontier in $\left(\mu_{p}, \sigma_{p}\right)$ space, we only need to find two efficient portfolios. The remaining frontier portfolios can then be expressed as convex combinations of these two portfolios.

Proposition I: Formulation of a frontier portfolio using two efficient portfolios [4].

Suppose $x=\left(x_{A}, x_{B}, x_{C}\right)^{\prime}$ and $y=\left(y_{A}, y_{B}, y_{C}\right)^{\prime}$ is any two minimum variance port-folios with different target expected returns, $x^{\prime} \mu=\mu_{p, 0} \neq y^{\prime} \mu=\mu_{p, 1}$. That is, portfolio x solves

$$
\min _{x} \sigma_{p, x}^{2}=\times^{\prime} \Sigma \times \text { s.t. } \times^{\prime} \mu=\mu_{p, 0} \text { and } x^{\prime} 1=1 .
$$

and portfolio y solves

$$
\min _{y} \sigma_{p, y}^{2}=y^{\prime} \Sigma y \quad \text { s.t. } y^{\prime} \mu=\mu_{p, 1} \text { and } y^{\prime} 1=1 .
$$

Suppose $\alpha$ is any constant and define the portfolio $z$ as a linear combination of portfolios, $x$ and $y$.

$$
z=\alpha \cdot x+(1-\alpha) \cdot y=\left(\begin{array}{c}
\alpha x_{A}+(1-\alpha) y_{A} \\
\alpha x_{B}+(1-\alpha) y_{B} \\
\alpha x_{C}+(1-\alpha) y_{C}
\end{array}\right)
$$

Then

1) The portfolio $\mathrm{z}$ is a minimum variance portfolio with expected return and variance given by

$$
\begin{gathered}
\mu_{p, z}=z^{\prime} \mu=\alpha \cdot \mu_{p, x}+(1-\alpha) \cdot \mu_{p, y} \\
\sigma_{p, z}^{2}=z^{\prime} \Sigma z=\alpha^{2} \alpha_{p, x}^{2}+(1-\alpha)^{2} \sigma_{p, y}^{2}+2 \alpha(1-\alpha) \sigma_{x y}
\end{gathered}
$$

where

$$
\sigma_{p, x}^{2}=x^{\prime} \Sigma \times, \quad \sigma_{p, y}^{2}=y^{\prime} \Sigma y, \quad \sigma_{x y}=x^{\prime} \Sigma y .
$$

2) If $\mu_{p, z} \geq \mu_{p, m}$, where $\mu_{p, m}$ is the expected return on the global minimum variance portfolio, then portfolio $z$ is an efficient portfolio. Otherwise, $z$ is an inefficient frontier portfolio. This particular derivation of portfolio frontier was carried out by another Nobel Laureate [24].

\section{Analysis and Discussion of Result}

The study begins by examining the descriptive results from the three selected companies. The result presented in Table 1 revealed that First Bank had a mean expected return of 18.29 percent followed by which had a mean expected returns of 17.73 per cent. The result observed that Cadbury had a mean expected return of 1.68 percent.

The result for standard deviation (which is the measure for the riskiness of the asset) revealed that First bank Nigeria, Guinness and Cadbury Nigeria Plc had standard deviation of 3.11, 2.73 and 3.26 respectively. Thus, Cadbury Nigeria Plc had the least return on asset but with the highest standard deviation. 
Table 1. Descriptive analysis for the first bank, Guinness Plc and Cadbury Nigeria Plc.

\begin{tabular}{cccc}
\hline & First Bank & Guiness & Cadbury Nig. Plc \\
\hline Mean & 0.182946 & 0.177362 & 0.016873 \\
Standard error & 0.139003 & 0.121943 & 0.145815 \\
Median & 0 & 0 & 0 \\
Mode & 0 & 0 & 0 \\
Standard deviation & 3.114431 & 2.732179 & 3.267054 \\
Sample variance & 9.699685 & 7.464806 & 10.673643 \\
Kurtosis & 35.714168 & 0.3697218 & 63.058922 \\
Skewness & -3.735929 & -0.112548 & -4.857296 \\
Range & 38.432755 & 19.487447 & 48.607188 \\
Minimum & -30.816619 & -9.84400 & -43.728172 \\
Maximum & 7.616136 & 9.844007 & 4.879016 \\
Sum & 91.839378 & 89.035734 & 8.470669 \\
\hline
\end{tabular}

Table 2 shows the collision of the mean, variance and covariance values for all the descriptive statistics on First Bank, Guinness and Cadbury. These values are used as aid in the optimization of the three assets portfolio.

Table 3 shows the Global Minimum result obtained from the returns. The portfolio weights are $x_{1}=0.29, x_{2}=0.40$ and $x_{3}=0.30$. The expected return of the portfolio is 0.13 . The variance is 3.39 and the standard deviation is 1.84 . This table represents the minimum risk portfolio for the three assets $\mathrm{A}, \mathrm{B}$ and $\mathrm{C}$.

Table 4 shows efficient portfolio result for First Bank Nigeria. The portfolio weights are $x_{1}=0.43, x_{2}=0.56$ and $x_{3}=-0.001 . \mu_{A}$ is the target rate of return with value of 0.18 . The variance has value of 4.76 and the standard deviation has value of 2.18 .

Table 5 shows efficient portfolio result for Guinness Nigeria. The portfolio weights are $x_{1}=0.40, x_{2}=0.53$ and $x_{3}=0.06 . \quad \mu_{B}$ is the target rate of return with value of 0.16 . The variance has value of 4.26 and the standard deviation has value of 2.06 . The value 4.26 for variance of asset $B$ indicates that asset $B$ has the lowest risk Table

Table 6 shows efficient portfolio result for Cadbury Nigeria. The portfolio weights are $x_{1}=-0.052, x_{2}=0.011$ and $x_{3}=1.04 . \quad \mu_{C}$ is the target rate of return with value of 0.016. The variance has value of 11.53 and the standard deviation has value of 3.39. The value 11.53 for variance of asset $C$ indicates that asset $C$ has the highest risk. The expected returns and variances are used to aid the selection of optimal portfolio.

Figure 1 represents the efficient frontier for three assets where the expected return is plotted against the risk. All efficient assets are above the Global Minimum which means that the frontier portfolio is efficient. All assets located above the Global Minimum at point $(\mu, \sigma)$ which is $(0.10,1.84)$ are efficient assets with high expected returns and low risk. These assets are preferred choice for every investor.

Figure 2 shows the risk and return trade-off for three asset portfolio. In this graph, the $\mathrm{y}$-axis shows the expected returns and the $\mathrm{x}$-axis shows the risk. It clearly 
Table 2. Mean, variance and covariance.

\begin{tabular}{cccccc}
\hline S/N & ASSET & E[R] & VAR & Cov & PAIRS(I,J) \\
\hline 1 & First Bank & 0.182946969 & 9.699685504 & 1.099998071 & $(1,2)$ \\
2 & Guinness & 0.177362022 & 7.464806402 & 0.343980153 & $(1,3)$ \\
3 & Cadbury & 0.016873844 & 10.673643803 & 0.199779782 & $(2,3)$ \\
\hline
\end{tabular}

Table 3. Global minimum variance portfolio.

\begin{tabular}{cccccc}
\hline & \multicolumn{5}{c}{ Portfolio weights } \\
\cline { 2 - 5 } & $x_{1}$ & $x_{2}$ & $x_{3}$ & Constraint & VAR(Rp) \\
\hline & 0.293640514 & 0.404530008 & 0.301829478 & 1 & 3.397026204 \\
$\mathrm{E}[\mathrm{Rp}, \mathrm{x}]$ & 0.1305633 & & & \\
$\mathrm{SD}(\mathrm{Rp}, \mathrm{x})$ & 1.843102331 & & & \\
\hline
\end{tabular}

Table 4. Efficient portfolio result for first bank Nigeria.

\begin{tabular}{ccccccc}
\hline Target & \multicolumn{2}{c}{ Portfolio weights } & & & & \\
\hline$\mu_{A}$ & $x_{1}$ & $x_{2}$ & $x_{3}$ & Constraint 1 & Constraint 2 & VAR(Rp) \\
\hline 0.1294 & 0.443565 & 0.556562 & 0.001282 & 1 & 0.1800009 & 4.7659114 \\
$\mathrm{E}[\mathrm{Rp}, \mathrm{x}]$ & 0.18000098 & & & & & \\
$\mathrm{SD}(\mathrm{Rp}, \mathrm{x})$ & 2.18309674 & & & & & \\
\hline
\end{tabular}

Table 5. Efficient portfolio result for Guinness Nigeria.

\begin{tabular}{ccccccc}
\hline Target & \multicolumn{2}{c}{ Portfolio weights } & & & & \\
\hline$\mu_{A}$ & $x_{1}$ & $x_{2}$ & $x_{3}$ & Constraint 1 & Constraint 2 & VAR(Rp) \\
\hline 0.17736 & 0.4069278 & 0.533036 & 0.060035 & 1 & 0.169999 & 4.268093 \\
$\mathrm{E}[\mathrm{Rp}, \mathrm{x}]$ & 0.1699999 & & & & & \\
$\mathrm{SD}(\mathrm{Rp}, \mathrm{x})$ & 2.0659364 & & & & & \\
\hline
\end{tabular}

Table 6. Efficient portfolio result for Cadbury Nigeria.

\begin{tabular}{ccccccc}
\hline Target & \multicolumn{2}{c}{ Portfolio weights } & & & & \\
\hline$\mu_{A}$ & $x_{1}$ & $x_{2}$ & $x_{3}$ & Constraint 1 & Constraint 2 & VAR(Rp) \\
\hline 0.01687 & -0.052694 & 0.0116674 & 1.04102 & 1 & 0.0100000 & 11.53808 \\
$\mathrm{E}[\mathrm{Rp}, \mathrm{x}]$ & 0.010000003 & & & & & \\
$\mathrm{SD}(\mathrm{Rp}, \mathrm{x})$ & 3.396775395 & & & & & \\
\hline
\end{tabular}

indicates Global Minimum, First Bank, Guinness, Cadbury and Capital Market Line (CML) drawn from the expected return of the efficient frontier. From the graph, Guinness lies on the capital market line with higher expected returns and lower risk at the point $(\mu, \sigma)$ which is $(0.16,2.06)$. First Bank is slightly away from the capital market line with higher returns and lower risk at $(\mu, \sigma)$ which is $(0.18,2.18)$. Cadbury is far away from the capital market line with lowest expected returns and highest risk at the 


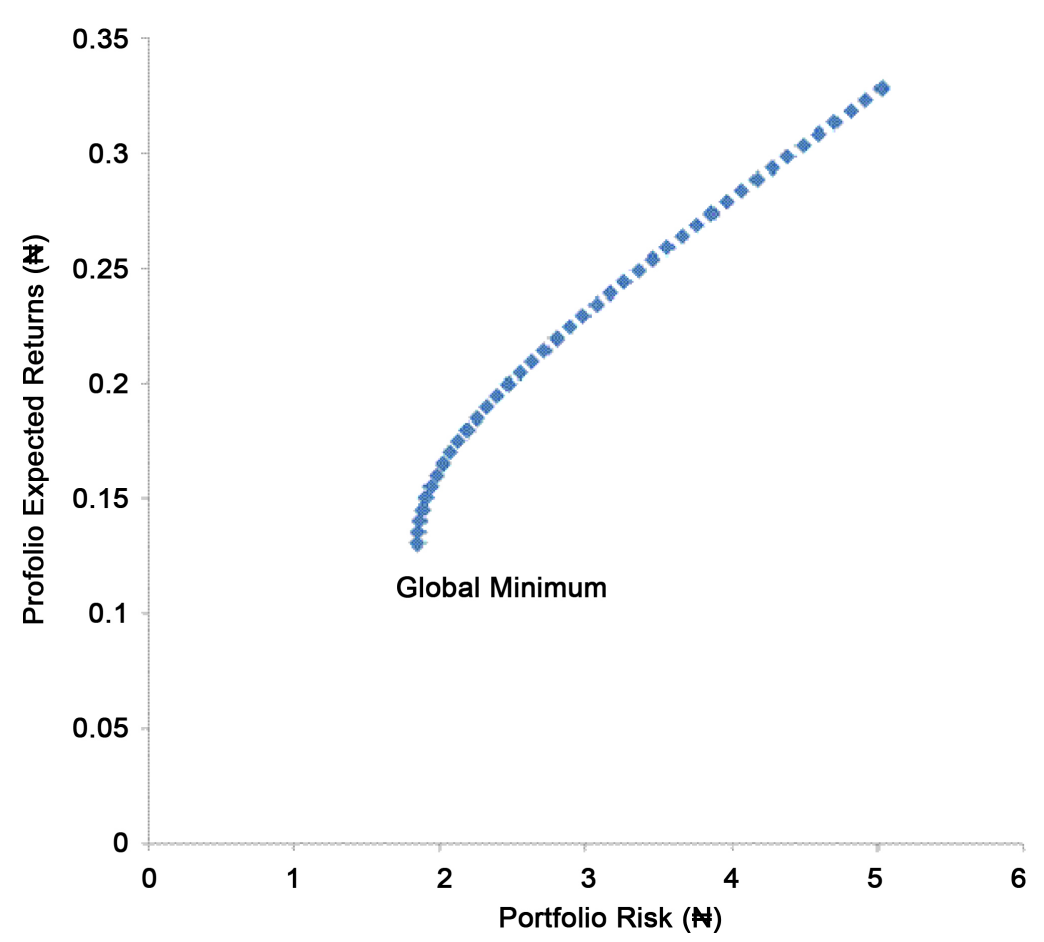

Figure 1. Efficient frontier for three assets.

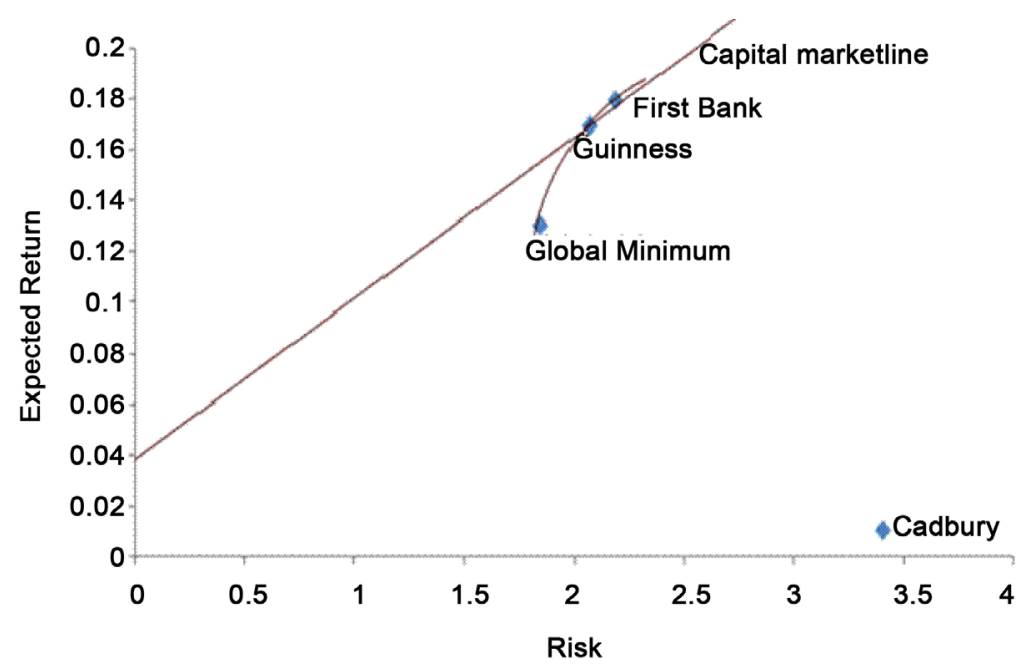

Figure 2. Risk and return tradeoff.

point $(\mu, \sigma)$ which is $(0.01,3.39)$. Therefore, among the three assets, Guinness Nigeria is the most efficient asset as indicated in the graph of efficient frontier.

\section{Summary}

The study has shown that among the three assets in the portfolio, two assets Guinness and First Bank are efficient optimal assets and Cadbury is the only inefficient asset in the portfolio. Guinness was observed to have the lowest risk of 4.268 while Cadbury had the highest risk of 11.538. The study affirmed that the Global Minimum Variance 
Portfolio provided a suitable and recommended aid in selecting optimal portfolio with expected return of 0.131 and variance of 3.397. The utility function test revealed that Guinness is an efficient optimal asset and the best company for investment since it has the highest utility value of 0.031 . In period of recession or deep economic doldrums, the asset of Guinness Nigeria Plc will still have the ability to provide some protection from an extreme loss even when other assets vale depreciates. A careful note of caution needs to be explained here that the research is not intended to lure investors to invest in Guinness Nigeria Plc, but rather to examine and explain how investors can select an optimal asset given a three-asset portfolio mix.

\section{References}

[1] Yahaya, A. (2012) On Numerical Solution for Optimal Allocation of Investment Funds in Portfolio Selection Problem. CBN Journal of Applied Statistic, 3.

[2] Roychoudhury, S. (2007) The Optimal Portfolio and the Efficient Frontier. Journal of Finance, 13-19.

[3] Reilly, F.K. and Brown, K.C. (2003) Investment Analysis and Portfolio Management. 7th Edition, Thomson South-Western, Australia.

[4] Zivot, E. (2013) Portfolio Theory with Matrix Algebra. Washington University, St. Louis. http://faculty.washington.edu/ezivot/econ424/PortfolioTheoryMatrixPowerpoint.pdf

[5] Markowitz, H.M. (1952) Portfolio Selection. Journal of Finance, 7, 77-91. http://dx.doi.org/10.1111/j.1540-6261.1952.tb01525.x

[6] D’Ambrosio, C.A (1976) Principles of Modern Investments. Science Research Associates Inc., Toronto.

[7] Chambernan, G. (1983) A Characterization of the Distributions That Imply Mean-Variance Utility Functions. Journal of Economics Theory, 29, 185-201. http://dx.doi.org/10.1016/0022-0531(83)90129-1

[8] Sharpe, W.F. (1995) Investment. 6th Edition, United Kingdom.

[9] Dobbins, R., Witt, S. and Fielding, J. (1996) Portfolio Theory and Investment Management: An Introduction to Modern Portfolio Theory. Blackwell Business, Great Britain.

[10] Corresia, C., Flynn, D., Ulianna, E. and Wormald, M. (2000) Financial Management. 4th Edition, Cape Town.

[11] Chandra, S. and Shadel W.G. (2007) Crossing Disciplinary Boundaries: Applying Financial Portfolio Theory to Model the Organization of the Self-Concept. Journal of Research Personal, 41, 346-373. http://dx.doi.org/10.1016/j.jrp.2006.04.007

[12] Levy, H. and Markowitz, H.M. (1979) Approximating Expected Utility by a Function of Mean and Variance. Journal of Finance, 3, 308-317.

[13] Pulley, L.B. (1981) A General Mean-Variance Approximation to Expected Utility for Short Holding Periods. Journal of Financial and Quantitative Analysis, 16, 361-373. http://dx.doi.org/10.2307/2330243

[14] Ulucan, A. (2007) An Analysis of Mean Variance Portfolio Selection with Varying Holding Periods. Applied Economics, 39, 1399-1407. http://dx.doi.org/10.2307/2330243

[15] Bomfim, A. (2001) Optimal Portfolio Allocation in a World without Treasury Securities. Finance and Economics Discussion Series. https://www.federalreserve.gov/pubs/feds/2001/200111/200111pap.pdf 
[16] Kisaka, S., Mbithi. J. and Kitur, H. (2015) Determining the Optimal Portfolio Size on the Nairobi Securities Exchange. Research Journal of Finance and Accounting, 6, 215-229.

[17] Boah, D.K., Adu, I. and Tulasi, V. (2015) Optimal Portfolio Mix for Multigrow Insurance Company in Ghana Using Linear Programming. International Journal of Mathematics and Statistics Studies, 3, 11-17.

[18] Bekkers, N., Doeswitz, R. and Lam, T. (2009) Strategic Asset Allocation: Determining Optimal Portfolio with Ten Asset Classes.

http://www.top1000funds.com/wp-content/uploads/2011/12/Strategic-Asset-Allocation.pdf

[19] Bhuyan, R., Kuhle, J., Ikromov, N. and Chiemeke, C. (2014) Optimal Portfolio Allocation among REITs, Stocks, and Long-Term Bonds: An Empirical Analysis of US Financial Markets. Journal of Mathematical Finance, 4, 104-112. http://dx.doi.org/10.4236/jmf.2014.42010

[20] Prasanna, C. (2008) Investment Analysis and Portfolio Management. 3rd Edition, Tata McGraw-Hill Education Private Limited, New Delhi.

[21] Farrell, J.I. (1983) Guide to Portfolio Management. McGraw-Hill, Companies Inc., New York.

[22] Benninga, S. (2006) Principles of Finance with Excel. Oxford University Press, Oxford.

[23] Udom, A.U. (2005) Essentials of Statistics. Magnet Business Enterprise, Enugu.

[24] Merton, R.C. (1972) An Analytical Derivation of the Efficient Derivation Portfolio Frontier. Journal of Finance and Quantitative Analysis, 10, 1851-1872.

http://dx.doi.org/10.2307/2329621

\section{Submit or recommend next manuscript to SCIRP and we will provide best service for you:}

Accepting pre-submission inquiries through Email, Facebook, LinkedIn, Twitter, etc.

A wide selection of journals (inclusive of 9 subjects, more than 200 journals)

Providing 24-hour high-quality service

User-friendly online submission system

Fair and swift peer-review system

Efficient typesetting and proofreading procedure

Display of the result of downloads and visits, as well as the number of cited articles

Maximum dissemination of your research work

Submit your manuscript at: http://papersubmission.scirp.org/

Or contact jmf@scirp.org 